\title{
Desempenho Zootécnico e Percentual de Consumo de Alimento de Rã-Touro (Rana catesbeiana) na Fase de Recria (Pós-Metamorfose) do Sistema Anfigranja ${ }^{1}$
}

\author{
Samuel Lopes Lima ${ }^{2}$, Alex Poeta Casali ${ }^{3}$, Cláudio Angelo Agostinho ${ }^{4}$
}

\begin{abstract}
RESUMO - Objetivou-se com este trabalho avaliar (em nível de campo) o desempenho zootécnico da rã-touro, Rana catesbeiana (Shaw, 1882), criada em ranários comerciais que utilizam o Sistema Anfigranja, e , simultaneamente, estimar os valores de consumo diário de alimento para compor uma tabela de referência para o arraçoamento dos animais. As avaliações demonstraram haver valores de produtividade com grandes variações, de acordo com a capacidade do produtor em assimilar a tecnologia e principalmente manejar os animais de forma padronizada, para atingir o ponto de equilíbrio no fluxo de produção de seu plantel. Os resultados encontrados nas unidades de observação monitoradas (aproximadamente 250 mil animais) atingiram os seguintes índices médios: a mortalidade (em \%) 0,5 a 39,5 (média geral 12,0); o ganho de peso (g./dia) 0,4 a 2,5 (média geral 1,2); e a conversão alimentar 0,9 a 2,5 : 1,0 (média geral 1,4 : 1,0). É apresentada uma tabela com os percentuais estimados de consumo de alimento, em função do peso médio dos animais, para o cálculo da quantidade de ração a ser oferecida diariamente.
\end{abstract}

Palavras-chave: índices zootécnicos, rã-touro, recria de rãs, Sistema Anfigranja, tabela de alimentação

\section{Performance and Food Intake of Bullfrogs (Rana catesbeiana) During the Post- Metamorphic Stage in the "Amphifarm" System}

\begin{abstract}
The objective of this work was to evaluate (under field conditions), the performance of bullfrogs (Rana catesbeiana) raised on commercial frog farms using the "Amphifarm" system and, at the same time, to estimate the daily food intake in order to obtain a reference table for feeding the animals. The results showed a large range in productivity, which varied according to the producer's capacity for assimilating technology and especially for handling animals in a standardized manner, in order to achieve a balance point in production. The results found on the observation units (approximately 250 thousand animals) showed the following indexes: mortality $(\%)$ ranged from 0.5 to 39.5 , the average being 12.0; weigh gain (g/day) ranged from 0.4 to 2.5 , the average being 1.2 ; and feed conversion ranged from 0.9 to 2.5 , the average being 1.4:1. The paper presents a table with estimated intakes as percentages of body weight to allow calculation of daily food offer.
\end{abstract}

Key Words: performance index, bullfrog, frog production, "Amphifarm" system, feeding table

\section{Introdução}

As características das instalações do Sistema Anfigranja de criação intensiva de rãs foram definidas a partir do desenvolvimento de vários protótipos, aliados às técnicas de manejo sistematizadas para cada um dos setores da criação: reprodução, girinos e recria. Tal sistema, proposto por Lima \& Agostinho $(1988,92)$, encontra-se ainda em fase de consolidação tecnológica apesar de estar em domínio público por alguns ranicultores.

O setor de recria de rãs desse sistema (local onde são alojadas as rãs, após a metamorfose) é composto de instalações (baias iniciais e de terminação) construídas com detalhes especiais para possibilitar o manejo dos animais com técnicas sistematizadas. $\mathrm{O}$ piso possui cocho, abrigo e piscina dispostos linearmente, oferecendo condições favoráveis para o crescimento dos animais (Lima \& Agostinho 1988, 1992).

Nos últimos anos, alguns detalhes de manejo e aperfeiçoamento nas instalações foram implementados, refletindo nos resultados de produtividade dos animais nos ranários que empregam o sistema (Lima et al., 1996; Lima, 1997). Nas instalações foram alteradas: o perfil do cocho para reduzir a perda do alimento, as duas piscinas foram agrupadas em uma única (central), com uma fileira de cochos e outra de abrigos, em cada lado, mantendo-se a largura padrão $(4,20 \mathrm{~m})$. Portanto, a disposição dos elementos básicos continuou linear, a baia ficou mais

\footnotetext{
1 Pesquisa parcialmente financiada pelo CNPq (bolsas aos pesquisadores)

2 Pesquisador visitante, bolsista do CNPq. E.mail: samuel.@ufv.br

3 Zootecnista, bolsista do CNPq. E.mail: apcasali@lince.tdnet.com.br

4 Professor FMVZ/UNESP - Botucatu - SP. E.mail: agostinho@fca.unesp.br
} 
versátil, ou seja, a alteração no desenho possibilitou que fossem alojados animais de qualquer tamanho em uma mesma baia, bastando a substituição dos abrigos (3 para $6 \mathrm{~cm}$ de altura) e a movimentação do nível d'água proporcionalmente ao crescimento dos animais (Lima \& Agostinho, 1995; Lima, 1997).

As rãs são animais pecilotérmicos, ou seja, o metabolismo varia de acordo com a temperatura do meio onde vivem (Brattstrom, 1979). Assim como outros organismos aquáticos pecilotérmicos que são cultivados (peixes, camarões, moluscos), o produtor tem sérias dificuldades de alimentar os animais adequadamente. Como as variações da temperatura afetam o consumo de alimento, observa-se que ora existe sobra de alimento, ora a oferta pode ser insuficiente.

Braga \& Lima (2001) verificaram o desempenho da rã-touro, em condições de laboratório, em ambiente com controle de temperatura, observando melhores resultados com $25 \pm 2^{\circ} \mathrm{C}$ e $30 \pm 2^{\circ} \mathrm{C}$. Figueiredo (1999) avaliou os efeitos do ambiente sobre aperformance de rã-touro em gaiolas de fibra de vidro, estimando melhores ganhos de peso à temperatura de $27,6 \mathrm{e}$ $30,1^{\circ} \mathrm{C}$ para rãs com peso inicial de 20 e $100 \mathrm{~g}$, e melhor crescimento a $28,2^{\circ} \mathrm{C}$. Demonstrou também que a temperatura interagiu com o fotoperíodo nos seus efeitos sobre o ganho de peso e crescimento corporal, peso e rendimento de carcaça, consumo de alimentos e conversão alimentar.

Os índices zootécnicos do desempenho de rãtouro criada no Sistema Anfigranja, em condições experimentais, estimados por Lima \& Agostinho (1988, e 1992), demonstraram valores médios de conversão alimentar 3:1 e 2:1 respectivamente; taxa de mortalidade valores mínimos próximos de 10 \%. Em 1997, Lima et al. apresentaram dados preliminares (em nível de campo) dos índices de produtividade de rãtouro no Sistema Anfigranja: mortalidade 4,54 a 24,09\% (média geral 9,95\%) excluídos os casos de mortandades provocadas por eventuais enfermidades ou erros de manejo; conversão alimentar 1,23 a 1,64:1,0 (média geral 1,46:1,0).

Para orientar no manejo alimentar, Lima \& Agostinho (1988) apresentaram uma tabela de referência baseada no percentual do peso médio dos animais. Tal tabela apresentava uma série de limitações: foi estabelecida em nível de laboratório (com temperatura controlada), ou seja, os animais não estavam sujeitos às variações climáticas diárias, particularmente a temperatura. Outro aspecto a ser considera- do é que a estimativa foi realizada com ração farelada, enquanto que atualmente a ração comercial utilizada pelos ranicultores é extruzada e em péletes. O que se observa na prática é que a tabela é de pouca utilidade para o ranicultor. O procedimento até então empregado, é a observação visual do tratador, de como foi o consumo do alimento no dia anterior (verificando a quantidade da sobra do alimento), aumentando ou diminuindo a quantidade a ser oferecida naquele dia, evidenciando a carência de uma tabela de referência mais prática para facilitar o manejo alimentar, uma das metas da presente avaliação.

Existem outros modelos de baias de recria de rãs além do proposto para o sistema anfigranja. Em levantamento realizado por Lima et al. (1999) identificaram, além do anfigranja os seguintes tipos (mais comuns) de baias de recria nos ranários brasileiros: confinamento, baia inundada e ranabox. Ainda existem desenhos ou modelos similares aos citados acima, porém modificados pelos próprios ranicultores, que ao construírem as instalações de seus ranários, o fazem com pequenas alterações dos modelos originais. Portanto, existem vários ranários que são similares ao anfigranja, similares ao confinamento, assim por diante. Infelizmente, dados de produtividade em tais modelos de baias não estão disponíveis na literatura.

A execução deste trabalho teve como objetivo a avaliação, em nível de campo, do desempenho zootécnico da rã-touro, Rana catesbeiana (Shaw, 1882) criada em ranários (comerciais) que utilizam o Sistema Anfigranja, e simultaneamente, estimar os valores da tabela de referência para o arraçoamento diário dos animais.

\section{Material e Métodos}

No período de março de 1997 a fevereiro de 2001, foram monitorados três ranários localizados respectivamente nos municípios de Anchieta (ES), Coimbra (MG) e em Visconde do Rio Branco (MG), aqui considerados como unidades de observação (respectivamente UO-1; UO-2 e UO-3). Em cada um deles, foram avaliados os índices zootécnicos de uma amostra da população de animais alojados nas baias de recria. A amostra foi constituída do monitoramento de todos animais alojados em determinadas baias (denominados de lotes), durante o período de permanência.

Em cada unidade de observação, vários lotes foram monitorados em baias escolhidas aleatoria- 
mente, totalizando 153 lotes avaliados, efetuando-se a biometria em aproximadamente 250 mil animais (baias com capacidade de alojar um a dois mil animais). Constam na Tabela 1 as características e respectivas capacidades de produção de cada unidade, por ciclo de produção, assim como o respectivo número de lotes monitorados durante o período.

Os desenhos ou modelos de cada baia seguiram as características descritas por Lima \& Agostinho (1988) e Lima (1997). Apesar de os ranicultores terem acesso às informações da tecnológicas, cada ranário foi construído com pequenas diferenças, de acordo com a criatividade de cada um. Portanto, a primeira iniciativa realizada foi a tentativa da correção ou adequação dessas diferenças, no sentido de padronizar tais características para minimizar a ação das variáveis físicas (instalações).

A densidade média utilizada nas baias foi de 50 rãs por metro quadrado. $\mathrm{O}$ desempenho das rãs foi avaliado através da análise dos dados coletados, em períodos de tempo variáveis referentes a: variação de peso, número de animais e quantidade de alimento oferecido em cada baia monitorada.

Para iniciar o monitoramento realizava-se a contagem e anotações do respectivo peso médio de animais a serem alojados em cada baia, e procedia-se a triagem ou separação por tamanho, no sentido de reduzir a variabilidade de peso entre os animais, tornando o grupo mais homogêneo. Infelizmente, por falta de um trabalho mais efetivo de melhoramento genético, esse procedimento ainda se faz necessário devido a grande variância no tamanho dos animais no plantel em criação nos ranários brasileiros.

As triagens foram realizadas com animais nas fases: inicial, crescimento e terminação, respectivamente com 50 g, 120 g, e acima de 180 g de acordo com Lima \& Agostinho (1988). Entretanto, na rotina do trabalho do ranário, nem sempre foi possível realizar triagens quando os animais estavam exata- mente nesses valores de peso e sim, próximos a essas faixas $( \pm 15 \%)$. O peso médio (inicial) dos imagos foi de $8 \mathrm{~g}$.

A definição da quantidade de alimento a ser oferecido aos animais obedeceu o seguinte procedimento: inicialmente o alimento foi oferecido em quantidade superior a capacidade de consumo, propiciando que os animais se alimentassem a vontade, mas que houvesse sempre uma pequena sobra. No dia seguinte anotava-se o respectivo peso do alimento que restava no cocho. Estabelecido o valor médio de consumo, rotineiramente pela manhã, o tratador verificava, em cada baia, a quantidade de alimento que não foi consumido (no dia anterior), aumentava ou mantinha a mesma quantidade, evitando que a sobra fosse superior a $10 \%$ do valor oferecido. O alimento era constituído de ração comercial para peixe carnívoro inicial (nas baias inicias) e de peixe carnívoro em terminação (nas baias de crescimento e terminação), adicionando-se um percentual de peso correspondente a 3 até $30 \%$ de larvas de mosca, como suplemento alimentar, de acordo com a proposta de Lima \& Agostinho (1984). As anotações da quantidade de alimento oferecido e mortes ocorridas em cada baia eram lançadas, diariamente, em fichas, para posterior processamento.

Durante o período de monitoramento, houve troca de procedência da ração, ou seja, cada ranicultor adquiriu de fabricantes diferentes, por razões de dificuldades de fornecimento regional e ou diferenças de preço. Na Tabela 2, apresentam-se os valores de garantia da formulação elaborada pelos fabricantes, em cada ração, e na Tabela 3, a lista das rações utilizadas em cada ranário, nas fases: inicial e terminação. Foi considerado que nessas situações, a comparação do desempenho, em cada ranário, era semelhante (em todos, utilizou-se ração para peixe carnívoro), apesar de prejudicar as comparações dos resultados entre os mesmos.

\begin{tabular}{|c|c|c|c|c|c|}
\hline $\begin{array}{l}\text { Ranários } \\
\text { Frog farm }\end{array}$ & $\begin{array}{l}\text { Altitude }(\mathrm{m}) \\
\text { Altitude }(\mathrm{m})\end{array}$ & $\begin{array}{c}\text { Temperatura } \\
\text { média da água }\left({ }^{\circ} \mathrm{C}\right) \\
\text { Water average } \\
\text { temperature }\left({ }^{\circ} \mathrm{C}\right)\end{array}$ & $\begin{array}{l}\text { Número } \\
\text { de baias } \\
\text { Number } \\
\text { of boxes }\end{array}$ & $\begin{array}{c}\text { Capacidade alojamento } \\
\text { (rãs por ciclo) } \\
\text { Shelter capacity } \\
\text { (frogs/cycle) }\end{array}$ & $\begin{array}{l}\text { Número de lotes } \\
\text { monitorados } \\
\text { Number of groups } \\
\text { observed }\end{array}$ \\
\hline UO-1 & 200 & 25 & 65 & 75.000 & 101 \\
\hline UO-2 & 650 & 20 & 14 & 12.000 & 41 \\
\hline UO-3 & 450 & 24 & 8 & 10.400 & 11 \\
\hline
\end{tabular}


Tabela 2 - Níveis de garantia indicados nas formulações de cada ração utilizada, em percentuais, para proteína bruta $(\mathrm{PB})$, extrato etéreo (EE), fibra bruta $(\mathrm{FB})$, minerais, cálcio $(\mathrm{Ca})$, fósforo $(\mathrm{P})$ e umidade

Table 2 - Guarantee levels indicated on the formulation of each diet used, in percentiles, for crude protein (CP), ether extract (EE), crude fiber (CF), minerals, calcium (Ca), phosphorus $(P)$ and humidity

\begin{tabular}{llcccccc}
\hline Ração & $\mathrm{PB}$ & $\mathrm{EE}$ & $\mathrm{FB}$ & Minerais & $\mathrm{Ca}$ & $\mathrm{P}$ & Umidade \\
Diet & $C P$ & $E E$ & $F B$ & Minerals & Ca & $P$ & Humidity \\
\hline $\mathrm{A}$ & 45 & 4 & 5 & 14 & 2,5 & 1 & 13 \\
$\mathrm{~B}$ & 45 & 4 & 6 & 14 & 3 & 1 & 12,5 \\
$\mathrm{C}$ & 44 & 7 & 6 & 13 & 3 & 1,5 & 10 \\
$\mathrm{D}$ & 42 & 7 & 4 & 15 & 3 & 1,3 & 10 \\
\hline
\end{tabular}

Em um dos ranários (U.O - 1), além de avaliar o desempenho, o monitoramento objetivou a identificação dos valores da tabela de referência para a oferta do alimento utilizando-se a ração A. De posse dos dados obtidos, estimou-se o percentual correspondente aos pesos médios dos animais e respectivos valores da quantidade do alimento oferecido, elaborando-se, assim, uma tabela de alimentação.

Tabela 3 - Rações comerciais utilizadas em cada ranário na estimativa dos índices zootécnicos

Table 3 - Commercial diet used on each frog farm in estimative of zootecnical indexes

\begin{tabular}{lcc}
\hline & Recria inicial & Recria final \\
\hline $\mathrm{UO}-1$ & $\mathrm{~A}$ & $\mathrm{~A}$ \\
$\mathrm{UO}-2$ & $\mathrm{~B}$ & $\mathrm{~B}$ \\
$\mathrm{UO}-3$ & $\mathrm{C}$ & $\mathrm{D}$ \\
\hline
\end{tabular}

\section{Resultados e Discussão}

Constam na Tabela 4 os valores médios da taxa de mortalidade, ganho de peso diário, e a conversão alimentar das rãs alojadas nas baias monitoradas nas unidades de observações avaliadas. Considerou-se aqui, conversão alimentar aparente, como a quantidade de alimento oferecido (em kg), dividido pelo ganho de peso ( $\mathrm{kg}$ de peso vivo).

Na Tabela 5, estão apresentados os dados classificados por etapas do crescimento (inicial, crescimento e terminação), em duas das unidades avaliadas (UO-1 e UO-2). Na unidade de UO-3, o volume de informação não possibilitou tal classificação.

Os resultados desta avaliação confirmaram a tendência das avaliações preliminares (Lima \& Agostinho, 1986, 1988, 1992 e 1995; Lima et al., 1997), mas demonstraram melhoria nos valores de conversão alimentar, o que representa redução nos custos da produção $(2: 1$ para $1,4: 1)$. Tal redução se deve não somente à melhoria na qualidade das rações oferecidas atualmente, mas, principalmente, aos benefícios dos ajustes efetuados no manejo de rotina, com a correta oferta do alimento.

O ganho de peso é influenciado pelas condições climáticas, ou seja, é fato conhecido que o metabolismo das rãs pode variar de acordo com a temperatura ambiente por ser um animal pecilotérmico. Como pode ser verificado, a unidade 2 (UO-2) apresentou os menores valores de ganho de peso diário, demonstrando a influência do micro-clima (menor temperatura) da região.

Tabela 4 - Valores mínimos, máximos e médios dos índices zootécnicos de rã-touro no Setor de Recria das três unidades monitoradas

Table 4 - Minimum, maximum and medium values of of bullfrog performance indexes of the three units

\begin{tabular}{|c|c|c|c|c|c|c|c|c|c|}
\hline \multirow[b]{2}{*}{$\begin{array}{l}\text { Ranário } \\
\text { Frog farm }\end{array}$} & \multicolumn{3}{|c|}{$\begin{array}{c}\text { Mortalidade }(\%) \\
\text { Mortality }(\%) \\
\end{array}$} & \multicolumn{3}{|c|}{$\begin{array}{c}\text { Ganho de peso diário }(\mathrm{g}) \\
\text { Daily weight gain }(\mathrm{g})\end{array}$} & \multicolumn{3}{|c|}{$\begin{array}{c}\text { Conversão alimentar (aparente) } \\
\text { Feed: gain ratio (apparent) }\end{array}$} \\
\hline & $\begin{array}{l}\text { Mínimo } \\
\text { Minimum }\end{array}$ & $\begin{array}{l}\text { Máximo } \\
\text { Maximum }\end{array}$ & $\begin{array}{l}\text { Média } \\
\text { Medium }\end{array}$ & $\begin{array}{l}\text { Mínimo } \\
\text { Minimum }\end{array}$ & $\begin{array}{l}\text { Máximo } \\
\text { Maximum }\end{array}$ & $\begin{array}{l}\text { Média } \\
\text { Medium }\end{array}$ & $\begin{array}{l}\text { Mínimo } \\
\text { Minimum }\end{array}$ & $\begin{array}{l}\text { Máximo } \\
\text { Maximum }\end{array}$ & $\begin{array}{l}\text { Média } \\
\text { Medium }\end{array}$ \\
\hline UO-1 & 1,2 & 60,5 & 13,5 & 0,5 & 2,8 & 1,4 & 0,7 & 2,4 & 1,3 \\
\hline UO-2 & 0,2 & 53,0 & 20,4 & 0,2 & 2,0 & 0,9 & 0,9 & 2,6 & 1,3 \\
\hline UO-3 & 0,0 & 5,1 & 2,0 & 0,5 & 1,9 & 1,2 & 1,0 & 2,4 & 1,6 \\
\hline $\begin{array}{l}\text { Média geral } \\
\text { General mean }\end{array}$ & 0,5 & 39,5 & 12,0 & 0,4 & 2,2 & 1,2 & 0,9 & 2,5 & 1,4 \\
\hline
\end{tabular}

R. Bras. Zootec., v.32, n.3, p.505-511, 2003 


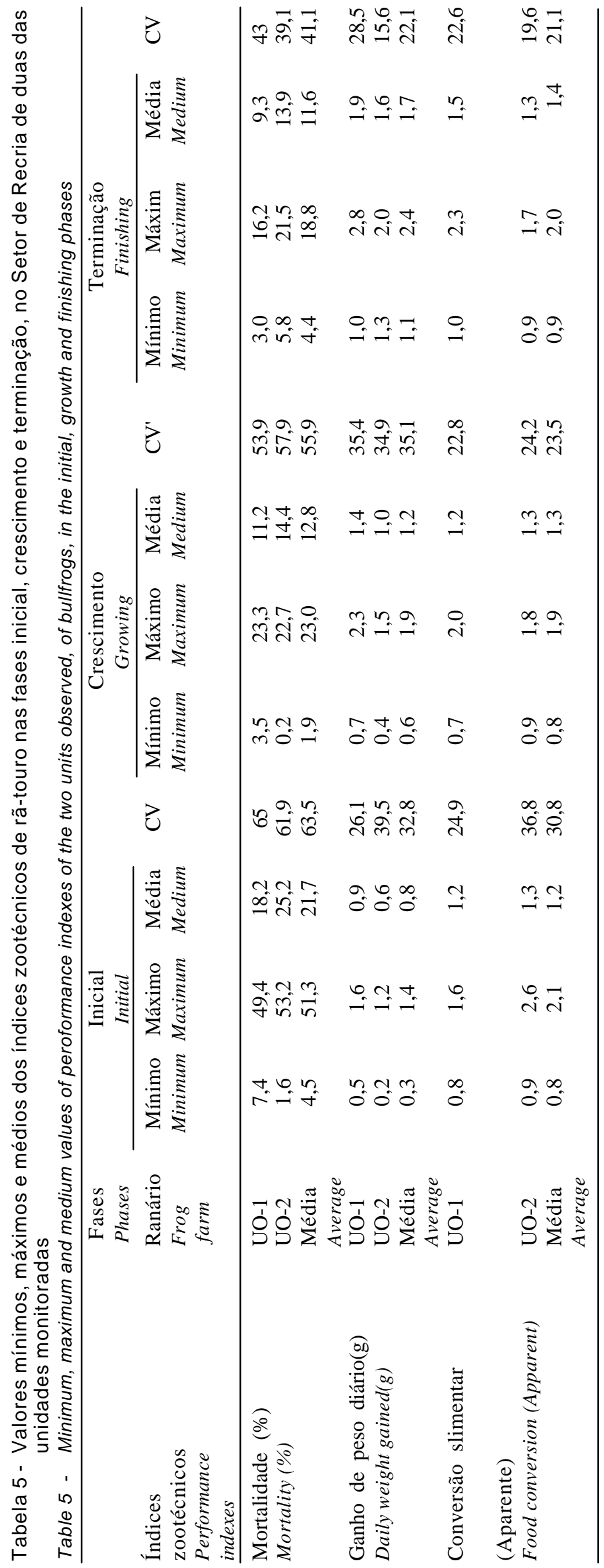


Tabela 6 - Tabela de alimentação: percentual de alimento oferecido em relação às faixas de peso médio de rã-touro criada no sistema anfigranja

Table 6 - Feeding table: offered food percentual, related to average weight of bullfrog raised at the Amphifarm System

\begin{tabular}{lccccccc}
\hline Faixa de peso $(\mathrm{g})$ & 8 a 19 & 20 a 29 & 30 a 39 & 40 a 109 & 110 a 149 & 150 a 209 & 210 a 230 \\
$\begin{array}{l}\text { Weight }(\mathrm{g}) \\
\begin{array}{l}\text { Percentual }(\%) \\
\text { Percentual }(\%)\end{array}\end{array}$ & 5,2 & 3,9 & 3,2 & 2,5 & 2,1 & 1,8 & 1,2 \\
\hline
\end{tabular}

A exemplo de outras criações de animais domésticos, o desempenho da rã-touro em cativeiro apresenta maior taxa de mortalidade e melhor conversão alimentar quando mais jovem (fase inicial). Na Tabela 6 , apresentam-se os percentuais de alimento oferecido (ração mais larva) em função do peso médio das rãs, contribuindo para ratificar a tabela anterior, proposta por Lima \& Agostinho (1988), agora com valores obtidos em nível de campo. Esta tabela possibilitará ao ranicultor efetuar o cálculo de alimento a ser oferecido diariamente. A tabela deve ser considerada como referência pois cada ranário deve apresentar valores diferenciados pois até o momento não existe uma padronização em todos eles quanto ao manejo alimentar, modelos de instalações, além das diferenças climáticas.

Os dados da tabela de alimentação seguem a mesma tendência de consumo inverso ao valor do peso, observada por Braga \& Lima (2001), com os seguintes percentuais para os respectivos pesos (\%/g): 12,18/8,5; 6,80/20; 4,24/40; 3,21/60 e 2,64/80. Apesar de as duas investigações terem sido realizadas em baias do sistema anfigranja, as diferenças entre os valores encontrados podem ser explicadas porquê uma foi realizada em nível de campo, sem nenhum tipo de controle das variáveis ambientais, e a outra em nível de laboratório, com a temperatura estabilizada em $25^{\circ} \mathrm{C}$.

A comparação com outros sistemas de criação, no que tange ao desempenho zootécnico da rã-touro fica prejudicada, em razão das poucas informações disponíveis na literatura, e das enormes diferenças quanto às condições ambientais (climáticas e físicas das instalações) e até mesmo a metodologia adotada.

A comparação entre o sistema anfigranja, confinamento, tanque ilha e gaiolas, simultaneamente em um mesmo local, foi realizada por Fontanello et al. (1993), demonstrando resultados inferiores ao obtidos nesta avaliação, no qual a baia do sistema anfigranja obteve índices de mortalidade de $28,92 \%$ na fase inicial, e 6,32\% na de crescimento/terminação, ganho de peso de 109, 57g. em 112 dias (ganho de peso médio estimado em $0,97 \mathrm{~g} / \mathrm{dia}$ ). Mesmo assim este sistema propiciou o melhor resultado de custo de produção $(0,94$ US $\$ / \mathrm{kg})$, e a maior produção por área, $4,09 \mathrm{~kg} / \mathrm{m}^{2}$.

A comparação em nível de ranário, com as baias inundadas pode ser efetuada com a avaliação preliminar feita por Mello (2000), de seis lotes de rãs, durante 85 dias: mortalidade de $37,4 \%$, ganho de peso médio 159,20 (1,87 g/dia), conversão alimentar média de 1,5:1. Carnevia et al (1995 e 1996) nos primeiros estudos com rã-touro em baias inundadas encontraram ganho de peso diário de $2,22 \mathrm{~g}$, conversão alimentar de 1,2:1 e mortalidade de $6 \%$.

Dados de desempenho de rã-touro em baias semelhantes ao "ranabox" foram divulgados por Rodriguez-Serna et al. (1996) no sistema de cultivo vertical-México, no qual obtiveram animais com peso final de $105 \mathrm{~g}$ após 175 dias de cultivo (0,66 g/dia) e mortalidade de $35 \%$, utilizando 525 rãs em densidade de $50 / \mathrm{m}^{2}$.

\section{Conclusões}

Os indicadores zootécnicos confirmaram a adequação das instalações e técnicas de manejo propostas para o Sistema Anfigranja, demonstrando a viabilidade da tecnologia, em escala de produção. A pouca disponibilidade de dados na literatura dificultou uma comparação mais detalhada deste sistema frente a outros modelos ou tipos de baias propostos por outros autores. A tabela de alimentação foi aferida, auxiliando nas estimativas de consumo, colaborando para as previsões de demanda de alimento no setor de recria, e favorecendo o ranicultor na compra e estocagem de ração. Deve ser levado em consideração que tais valores estimados para a tabela de alimentação devem ser recalculados toda vez que houver o emprego de rações de qualidade nutricional distintas da empregada nesta pesquisa (ração extrusada para peixe carnívoro, com $45 \%$ de $\mathrm{PB}$ ). $\mathrm{O}$ procedimento de 
observação direta do tratador, do consumo do alimento, deve ser um recurso importante para o cálculo da oferta de ração, procurando não exceder $10 \%$ de sobra. Outro fato conhecido e que deve ser levado em consideração, são os fatores climáticos regionais, principalmente a temperatura, que afetam o metabolismo das rãs, acelerando ou reduzindo a velocidade do crescimento, influindo no desempenho zootécnico dos animais. Foi evidenciada a necessidade de um esforço adicional dos técnicos de assistência técnica, junto aos ranicultores, para a padronização das instalações e técnicas de manejo.

\section{Literatura Citada}

BRAGA, L.G.T.; LIMA, S.L. Influência da temperatura ambiente no desempenho da rã-touro, Rana catesbeiana (Shaw, 1802), na fase de recria. Revista Brasileira de Zootecnia, v.30, n.6, p.1659-1663, 2001.

BRATTSTROM, B.H. Amphibian temperature regulations studies in the field and laboratory. American Zoological, v.19 (único), p.345-356, 1979.

CARNEVIA, D.; ROSSO, A.; MAZZONI, R. Primeiro estúdio de crecimiento de ranas em "sistema inundado". Boletim IIP n.13, p.55-56, 1996.

FIGUEIREDO, M.R.C. Influência dos fatores ambientais sobre o desempenho da rã-touro (Rana catesbeiana) em gaiolas. Viçosa, MG: Universidade Federal de Viçosa, 1996. 149p. Dissertação (Doutorado em Zootecnia) - Universidade Federal de Viçosa, 1996.

FONTANELLO, D.; WIRZ, R.R.; SOARES, H.A. et al. Comparação de quatro sistemas de engorda de rãs-touro (Rana catesbeiana, Shaw, 1802): tanque-ilha, confinamento, anfigranja e gaiolas. Desenvolvimento ponderal; custo operacional. Boletim Instituto de Pesca, 20 (único), 1993.

LIMA, S.L. Criação de rãs em anfigranjas. Viçosa, MG: Centro de Produções Técnicas, 1997. 37p. (Manual Técnico, 35)

LIMA S.L.; AGOSTINHO, C.A. Técnicas de alimentação de rãs. Viçosa, MG: Universidade Federal de Viçosa, 1984. (Informe Técnico, 54)
LIMA, S.L.; AGOSTINHO, C.A. A criação de rãs. Rio de Janeiro: Editora Globo, 1988. 172p.

LIMA, S.L.; AGOSTINHO, C.A. Índices de produtividade da rãtouro, Rana Catesbeiana, em Anfigranja. In: ENCONTRO NACIONAL RANICULTURA, 6., 1986, Porto Alegre. Anais... Rio de Janeiro: Associação dos Ranicultores do Estado do Rio de Janeiro, 1986. p.8-12.

LIMA, S.L.; AGOSTINHO, C.A. Ganho de peso e conversão Alimentar da rã-touro, Rana Catesbeiana, com racão (Ensaios preliminares). In: ENCONTRONACIONALRANICULTURA, 7., 1988, Rio de Janeiro. Anais... Rio de Janeiro:Associação dos Ranicultores do Estado do Rio de Janeiro, 1988. p.35-40.

LIMA, S.L.; AGOSTINHO, C.A. A tecnologia de criação de rãs. Viçosa, MG: Universidade Federal de Viçosa, 1992. 168p.

LIMA, S.L.; AGOSTINHO, C.A, Evolução das instalações e do manejo no setor de recria ou fase pós-metamorfica do Sistema Anfigranja, In: TECHNOFROG'95, 1995, Viçosa, MG. Resumos... Academia de Estudos Técnicos em Ranicultura, Viçosa, 1995. p.95-95.

LIMA, S.L.; VALLES, G.A.; BRAGA, G.T. Manejo em Anfigranjas. Viçosa, MG: Centro de Produções Técnicas, Centro de Produções Técnicas, 1996.34p. (Manual Técnico, 8)

LIMA, S.L.; LANZA, A.L.; CASALI, A.P. et al. Sistema anfigranja: índices de produtividade com rã-touroRana catesbeiana. In: TECHNOFROG' 97, 1997, Santos.Anais... Santos: Academia de Estudos Técnicos em Ranicultura, 1997. p.198-199.

LIMA, S.L; CRUZ, T.A.; MOURA, M.O. Ranicultura: análise da cadeia produtiva. Viçosa, MG: Editora Folha de Viçosa, 1999. 170p.

MELO, S.R. Crescimento de rã-touro em baias inundadas. Revista Panorama da Aqüicultura, v. 8, n.50, p. 15-17, 1997.

RODRIGUES-SERNA, M.; FLORES-NAVA, A.; OLIVERANOVOA, A. et al. Growth and production of bullfrog Rana catesbeiana (Shaw, 1802) at three stocking densities in a vertical intensive culture system. Aquicultural Engineering, v.15, n.4, p.233-242, 1996.
Recebido em: 18/12/01 Aceito em: 13/11/02 